\title{
Source processes of the foreshock, mainshock and largest aftershock in the 2003 Miyagi-ken Hokubu, Japan, earthquake sequence
}

\author{
Kazuhito Hikima $^{1,2}$ and Kazuki Koketsu ${ }^{1}$ \\ ${ }^{1}$ Earthquake Research Institute, University of Tokyo, 1-1-1 Yayoi, Bunkyo-ku, Tokyo 113-0032, Japan \\ ${ }^{2}$ OYO Corporation, 2-61-5 Toro-cho, Kita-ku, City of Saitama, Saitama 331-0804, Japan \\ (Received October 28, 2003; Revised January 27, 2004; Accepted February 5, 2004)
}

\begin{abstract}
The waveform inversions for the 2003 Miyagi-ken Hokubu earthquake sequence were performed using strongmotion records to determine the source processes. We carried out the inversions for the foreshock (M5.6), the mainshock (M6.4) and the largest aftershock (M5.5), respectively. The strong-motion waveforms observed at 10 stations from KiK-net and K-NET within about $70 \mathrm{~km}$ epicentral distance were used. The mainshock is composed of two subplanes dipping toward west. The strike direction of the south subplane is NE-SW and that of the north subplane is almost N-S. The fault plane of the foreshock is almost the same as that of the south subplane of the mainshock, but the strike direction of the largest aftershock is NW-SE. The asperities of the three earthquakes are not overlapped strongly each other and it is considered that this earthquake sequence is a result of seismic activity on a reverse fault, which is curved along strike, with time lags. The shallow asperity of the mainshock may result in specific distributions of damage and high accelerations.
\end{abstract}

Key words: Source process, waveform inversion, strong motion, earthquake sequence.

\section{Introduction}

At 7:13 a.m. on July 26, 2003 (JST $=$ UT +9 hours), an $M_{\mathrm{JMA}} 6.4$ earthquake occurred in the northern part of the Miyagi prefecture, northeastern Japan (JMA: Japan Meteorological Agency, 2003). This mainshock was associated with a distinct foreshock and vital aftershock activities. They form an earthquake sequence, which will be called 'the 2003 Miyagi-ken Hokubu earthquake sequence' in this study. The foreshock just seven hours before the mainshock had an $M_{\text {JMA }}$ of 5.6, while the largest aftershock occurred at 16:56 about ten hours after the mainshock with an $M_{\mathrm{JMA}}$ of 5.5 (Table 1).

The distribution of the epicenters in Fig. 1 shows that the foreshock and mainshock are located close to each other. The fault plane solutions of these events determined by NIED (National Research Institute for Earth Sciences and Disaster Prevention, 2003) from first $P$-motion polarity data are also indicating reverse faulting in the NW-SE direction (Table 1). However, the largest aftershock is $10 \sim 15 \mathrm{~km}$ away from the preceding events, and its $P$-axis points to the NE and SW. In addition, if we compare the fault plane solutions and the CMT solutions obtained by NIED with the method of Fukuyama et al. (1998) (CMT solution in Table 1), it is found that those of the foreshock are alike, but the solutions of the mainshock are rather different from each other.

These features of the focal mechanism, which were also obtained by Yamanaka and Kikuchi (2003), should come from complexities of the source processes in the 2003 Miyagi-ken Hokubu earthquake sequence. The seismic in-

Copy right (C) The Society of Geomagnetism and Earth, Planetary and Space Sciences (SGEPSS); The Seismological Society of Japan; The Volcanological Society of Japan; The Geodetic Society of Japan; The Japanese Society for Planetary Sciences; TERRAPUB. tensity meters (JMA, 1996) at some sites in the source region reported $6+$, which may correspond to $\mathrm{X}$ in the modified Mercalli intensity scale, and accelerations higher than 1000 gal during the mainshock. Since the earthquake sequence occurred in a shallow part of the crust, complexities in the source processes may directly result in these ground motions. Thus, we will carry out source process inversions of strong motion records to infer the details of slip distributions and rupture histories on the source faults. We will then discuss the relations among the foreshock, mainshock and largest aftershock, and the effects of the source processes on the observed strong ground motions.

\section{Data and Method}

The K-NET (Kinoshita, 1998) and KiK-net (Aoi et al., 2000) are nation-wide arrays of strong-motion seismometers operated by NIED, which cover the whole country in the same quality with almost homogeneous density. In particular, the KiK-net consists of borehole instruments as well as surface ones at all of the stations. The former is installed in a borehole $100 \mathrm{~m}$ or more deep to avoid the site effect of shallow soil conditions on seismograms. Moreover, velocity logging was carried out at every station. It can provide very useful information to make underground structure models for calculating Green's functions. Therefore, we use threecomponent borehole seismograms at the nine KiK-net stations plotted with black triangles in Fig. 1. Since there is no KiK-net station in the southeast of the source region, we also use seismograms at MYG011 of K-NET, which is the only station in this direction. The seismograms were recorded by accelerometers and numerically integrated to obtain velocity waveforms. The resultant velocities are filtered out with a pass band of $0.05-0.5 \mathrm{~Hz}$, and re-sampled with an interval of 
Table 1. Preliminary hypocenters, magnitudes, maximum intensities and mechanisms of the foreshock, mainshock and largest aftershock (JMA, 2003; NIED, 2003). The uncertainty of the mechanism solutions is discussed in Fukuyama et al. (1998).

\begin{tabular}{cccccccccccccc}
\hline Time & Latitude & Longitude & Depth & $M_{\mathrm{JMA}}$ & \multicolumn{2}{c}{ Maximum } & \multicolumn{4}{c}{ CMT solution } & \multicolumn{4}{c}{ Fault plane solution } \\
& & & & & intensity & strike & dip & rake & depth & $M_{\mathrm{W}}$ & strike & dip & rake \\
\hline $00: 13: 08.3$ & $38^{\circ} 25.9^{\prime}$ & $141^{\circ} 10.1^{\prime}$ & $12 \mathrm{~km}$ & 5.6 & $6-$ & $209^{\circ}$ & $54^{\circ}$ & $92^{\circ}$ & $5 \mathrm{~km}$ & 5.6 & $207^{\circ}$ & $58^{\circ}$ & $76^{\circ}$ \\
$07: 13: 31.5$ & $38^{\circ} 24.1^{\prime}$ & $141^{\circ} 10.5^{\prime}$ & $12 \mathrm{~km}$ & 6.4 & $6+$ & $186^{\circ}$ & $52^{\circ}$ & $88^{\circ}$ & $5 \mathrm{~km}$ & 6.4 & $232^{\circ}$ & $45^{\circ}$ & $112^{\circ}$ \\
$16: 56: 44.5$ & $38^{\circ} 29.8^{\prime}$ & $141^{\circ} 11.6^{\prime}$ & $12 \mathrm{~km}$ & 5.5 & $6-$ & $131^{\circ}$ & $39^{\circ}$ & $101^{\circ}$ & $5 \mathrm{~km}$ & 5.5 & $153^{\circ}$ & $49^{\circ}$ & $153^{\circ}$ \\
\hline
\end{tabular}

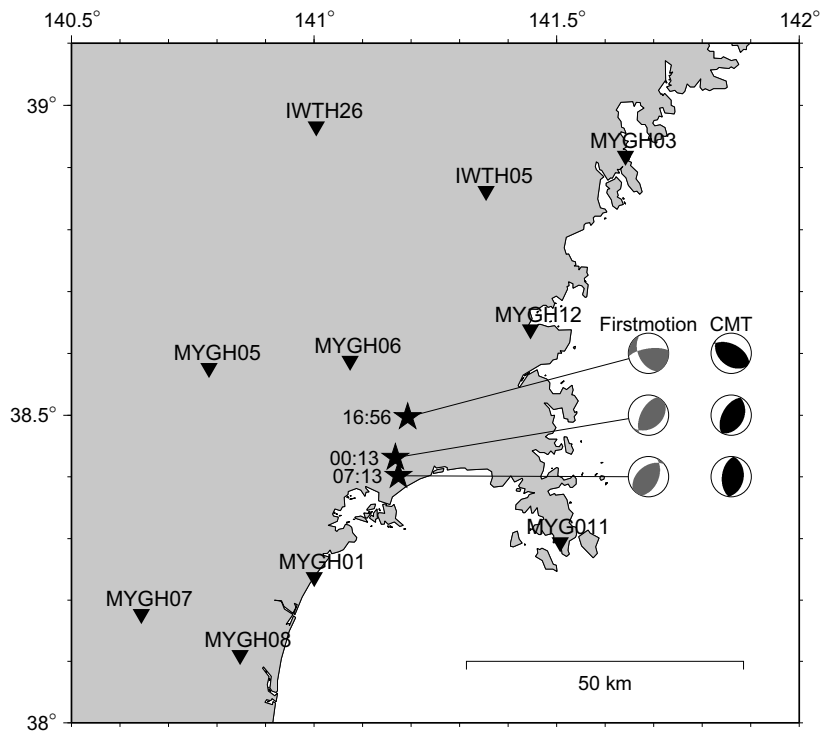

Fig. 1. The JMA epicenters of the 2003 Miyagi-ken Hokubu earthquake sequence (stars) and the stations of KiK-net and K-NET used for waveform inversion (reverse triangles). The origin times are written by the side of the epicenters. The fault plane solutions from first motion data and the CMT solutions determined by NIED (2003) are also plotted. MYG011 belongs to K-NET and the others are KiK-net stations.

$0.2 \mathrm{~s}$.

Yoshida et al. (1996) developed a waveform inversion method based on the formulation of multiple time window (e.g., Olson and Apsel, 1982). Fault planes are assumed and they are divided into subfaults with point slips at their centers. Since the slip orientation in the earthquake sequence has already been found to be of reverse faulting (see the rake angles in Table 1), the slip vector on a subfault is represented by a linear combination of two components in the directions of $90 \pm 45^{\circ}$. We stabilize the inversion by imposing smoothness constraints with the discrete Laplacian in space and time:

$$
\begin{aligned}
\nabla^{2} X_{m n l} & =X_{m+1, n, l}+X_{m, n+1, l}+X_{m, n, l+1} \\
& +X_{m-1, n, l}+X_{m, n-1, l}+X_{m, n, l-1}-6 X_{m, n, l}
\end{aligned}
$$

where $X_{m n l}$ is the slip on the $m n$-th subfault in the $l$-th time window. The weights of smoothness constraint is determined by using ABIC (Akaike, 1980). To confine the slip angles within $90 \pm 45^{\circ}$, we introduce the penalty function $1 / \sqrt{X}$ (e.g., Koketsu, 1989) and build a constraint as

$$
1 / \sqrt{X_{m n l}} \sim 1 / \sqrt{X^{0}}
$$

where $X^{0}$ is an initial guess of the slip component obtained from other analyses such as the CMT solutions.
Table 2 . Velocity structure.

\begin{tabular}{ccc}
\hline Thickness $(\mathrm{km})$ & $V_{\mathrm{P}}(\mathrm{km} / \mathrm{s})$ & $V_{\mathrm{S}}(\mathrm{km} / \mathrm{s})$ \\
\hline 1.5 & \multicolumn{2}{c}{ varying } \\
12.5 & 6.3 & 3.5 \\
6.0 & 6.5 & 3.65 \\
13.0 & 7.0 & 4.0 \\
$\infty$ & 7.7 & 4.4 \\
\hline
\end{tabular}

We use the reflectivity method of Kohketsu (1985) to calculate the Green's functions, and it is extended to buried receivers to calculate borehole seismograms from the KiK-net. This method is only for one-dimensionally stratified structures, but the stations are located in various site conditions. For example, some stations are situated in the Kitakami massif, where the basement is exposed to the surface, and others are located in the Sendai basin, where thick sediments cover the bedrocks. Therefore, we use a set of velocity structures introducing a common part below a depth of $1.5 \mathrm{~km}$ as shown in Table 2. This part is determined from Iwasaki et al. (1994) and the model for the Tohoku University seismic network (Hasegawa et al., 1978).

The varying shallower part is modeled by using the results of velocity logging and the structure used in strong motion prediction for a future Miyagi-ken Oki earthquake by the Headquarters for Earthquake Research Promotion (2003). These structures will also vary the shallow part of source region. However, because all subfaults are located below a depth of $1.5 \mathrm{~km}$, the structure models in the source region are same for all stations. To reduce possible artifacts due to the incompleteness of the velocity structure, scalar time shifts are added to the Green's functions, and their values are also determined by the inversion.

\section{Source Model}

In order to perform a waveform inversion, it is necessary to set up a fault plane in advance. The first motion mechanisms (fault plane solutions in Table 1) indicate that the mainshock and foreshock were generated by reverse faulting of NE-SW strike. However, Yamanaka and Kikuchi (2003) and the CMT solution in Table 1 suggest reverse faulting of $\mathrm{N}-\mathrm{S}$ strike for the main shock. The first motion mechanism reflects the fault motion from the initial rupture while the CMT solution reflects the overall motion of the fault from the area with the most seismic moment release. So this difference implies that, for the mainshock, the large-slip zone has different orientation from the slip around the initial fault 
Table 3. Assumed fault parameters for the inversion.

\begin{tabular}{lcccc}
\hline & Strike & Dip & Length $(\mathrm{km})$ & Width $(\mathrm{km})$ \\
\hline Foreshock & $\mathrm{N} 220^{\circ} \mathrm{E}$ & $45^{\circ}$ & 10 & 10 \\
Mainshock (South) & $\mathrm{N} 220^{\circ} \mathrm{E}$ & $45^{\circ}$ & 6 & 10 \\
\multicolumn{1}{c}{ (North) } & $\mathrm{N} 186^{\circ} \mathrm{E}$ & $52^{\circ}$ & 12 & 10 \\
Aftershock & $\mathrm{N} 131^{\circ} \mathrm{E}$ & $39^{\circ}$ & 6 & 6 \\
\hline
\end{tabular}

break. The CMT solution and first motion mechanism of the foreshock are almost the same and they resemble the first motion mechanism of the mainshock. On the other hand, unlike the mainshock and foreshock, the largest aftershock was generated by reverse faulting of NW-SE strike as shown in Table 1 and in Fig. 1.

The Tohoku university conducted temporal seismic observations immediately after the largest aftershock just above the source region of the earthquake sequence, and preliminarily reported the distribution of aftershocks (Tohoku University, 2003). According to this report, the aftershocks are distributed on a $50^{\circ}$ west- or northwest-dipping plane. Okada et al. (2003) relocated the aftershocks using the double difference method (Waldhauser and Ellsworth, 2000) and found that the strike of the plane changed from NE-SW in the south to $\mathrm{N}-\mathrm{S}$ in the north.

Based on these results, the fault plane used in a waveform inversion are set up as follows. We divide the plane into northern and southern subplanes, and locate them so that the southern subplane includes the hypocenter of the mainshock. The depth of the fault plane is determined from the aftershock distribution by Tohoku University (2003) as the hypocenter is located at a depth of $6.5 \mathrm{~km}$. The strikes and dips are determined from the CMT and fault plane solutions of the mainshock in Table 1. The foreshock is also assumed to have been ruptured within the southern subplane, but its hypocenter is on the northern tip, so the subplane will be expanded to the north and west for the foreshock inversion. We introduce another subplane for the largest aftershock. Its geometry is determined from the CMT solution in Table 1 again, but somewhat adjusted according to the results of preliminary inversions.

The above setup is summarized in Fig. 2 and Table 3. The subplanes are divided into $2 \times 2 \mathrm{~km}^{2}$ subfaults and point dislocations are located at their centers. The amounts of dislocations (slips) are determined by the waveform inversions. We assume that the rupture started at the hypocenters and the epicenters by JMA are used for their horizontal coordinates. We have carried out the preliminary inversions with rupture velocities of $2.4,2.6,2.8$ and $3.0 \mathrm{~km} / \mathrm{s}$ and find that $3.0 \mathrm{~km} / \mathrm{s}$ produces the best result for the mainshock, and $2.8 \mathrm{~km} / \mathrm{s}$ is the best for the foreshock and the largest aftershock. However, the difference of the result is not so large, so it may be said that a range of rupture velocities produce acceptable waveform fits.

\section{Results}

\subsection{Foreshock}

Figure 3(a) shows a surface projection of the slip distribution of the foreshock. The star symbol in the figure de-

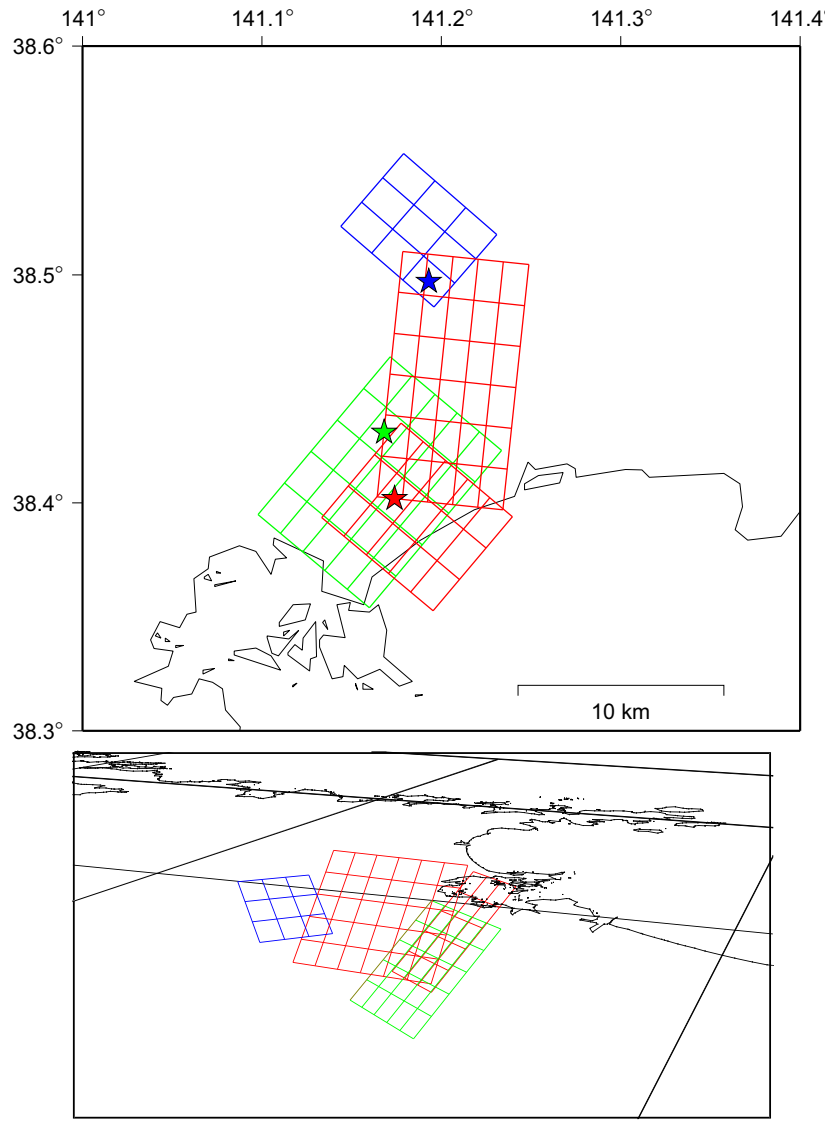

Fig. 2. Upper: surface projection of the assumed fault planes for the inversion analysis. The stars denote epicenters. Green, red and blue colors indicate the foreshock, the mainshock and the largest aftershock, respectively. Lower: bird's-eye view of the fault planes from SW direction.

notes the initial break of rupture (epicenter by JMA). The hypocentral depth is determined to be $9 \mathrm{~km}$ from the aftershock distribution by Tohoku University (2003). Only very small slips are recovered around the hypocenter. The rupture propagated toward the southern shallow portion of the subplane, where a slip of $0.2 \mathrm{~m}$ is recovered. The total seismic moment is $2.2 \times 10^{17} \mathrm{Nm}\left(M_{\mathrm{W}} 5.5\right)$, which is almost the same as that by the CMT inversion of NIED (Table 1). The total source duration is about $5 \mathrm{~s}$. We also plot the JMA epicenters of aftershocks with magnitudes of two or larger in the period between the foreshock and the mainshock. They are mostly distributed in the area connecting the hypocenter and large-slip zone. The JMA locations of the aftershock epicenters include an error of $0.4 \mathrm{~km}$ in average (JMA, 2003), which is sufficiently smaller than the subfault spacing in our source model. The horizontal coordinates of the JMA locations fairly agree with those of the Tohoku university locations, while the JMA and Tohoku university (2003) use different crustal structures. This implies that the structure does not affect the horizontal locations of the aftershocks so much. The seismograms synthesized from the recovered slip distribution (black traces) are compared with the observed seismograms (red traces) in Fig. 4. Most of the features in the observation are reconstructed in the synthetics, but the waveforms at MYGH05 and MYGH07 do not show good agreement. These stations are in a sedimentary basin and the 

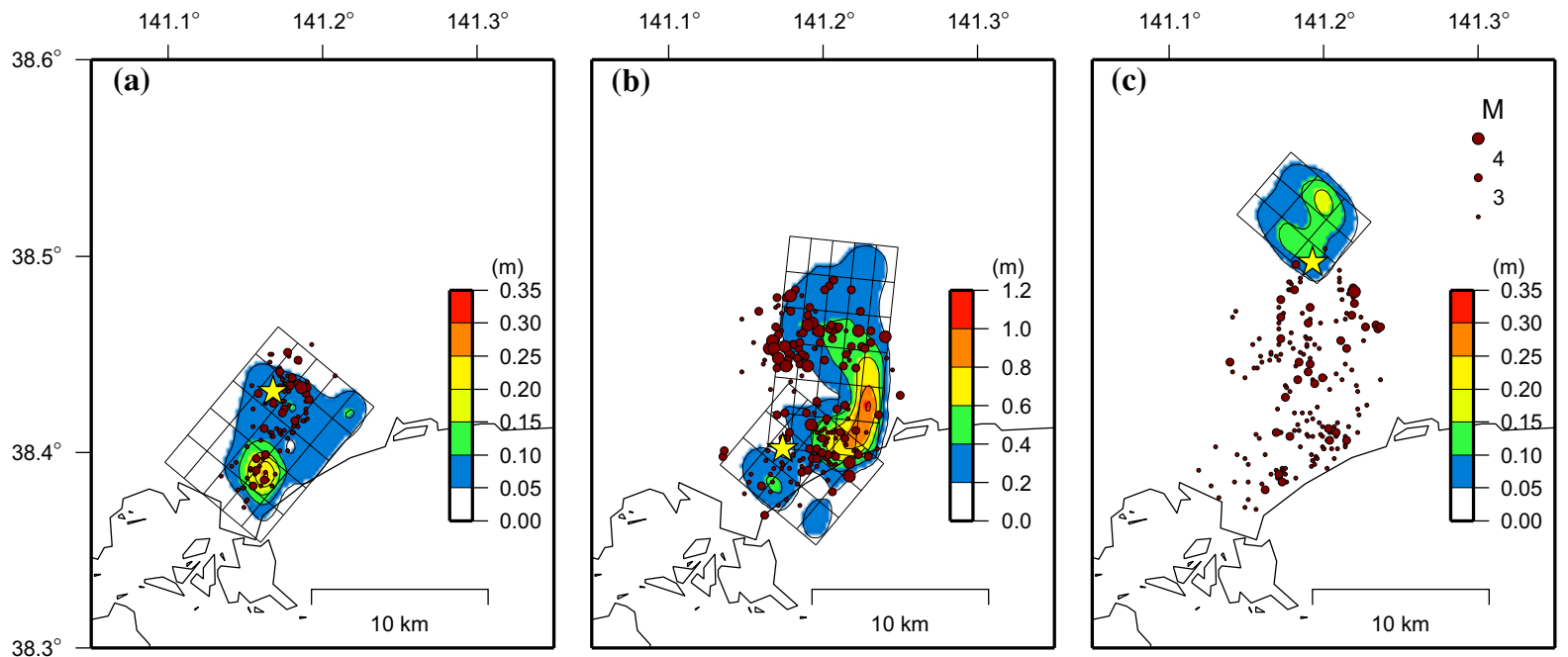

Fig. 3. (a): Surface projection of the recovered slip distribution for the foreshock. The epicenter is shown with a star symbol. The aftershocks with magnitude 2 or larger in the period between the foreshock and the mainshock are also plotted. (b): Same as (a) but for the mainshock. The aftershocks in the period between the mainshock and largest aftershock shock are plotted. (c): Same as (a) but for the largest aftershock. The aftershocks after the largest one on July 26 and 27 are plotted.
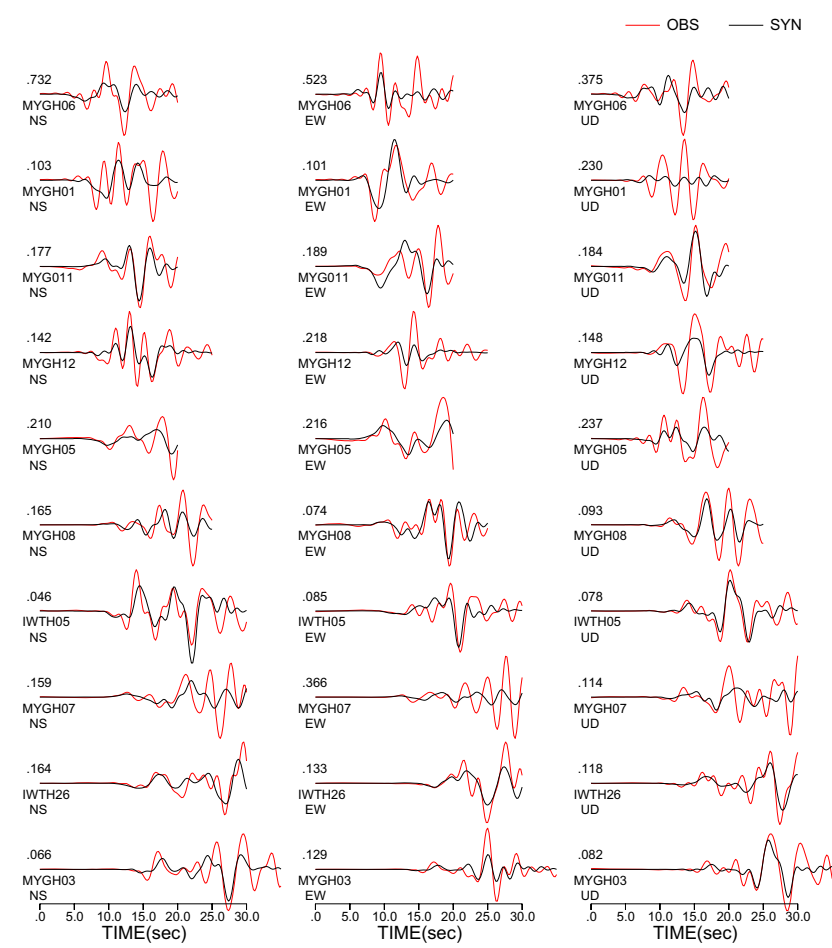

Fig. 4. Comparison of the observed velocity seismograms (red traces) and synthesized ones (black traces) for the foreshock. The maximum velocity is indicated in units of $\mathrm{cm} / \mathrm{s}$ above the station code. The tick marks are plotted in every 5 seconds.

1-D structures for them may not represent the basin perfectly.

\subsection{Mainshock}

As mentioned in the previous section, the hypocenter of the mainshock is located at a depth of $6.5 \mathrm{~km}$, and the fault plane is divided into the northern and southern subplanes. We have performed several preliminary inversions and confirmed that the source model based on these assumptions gives the best fit, compared to models with a deeper or shallower hypocenter and single-fault models.
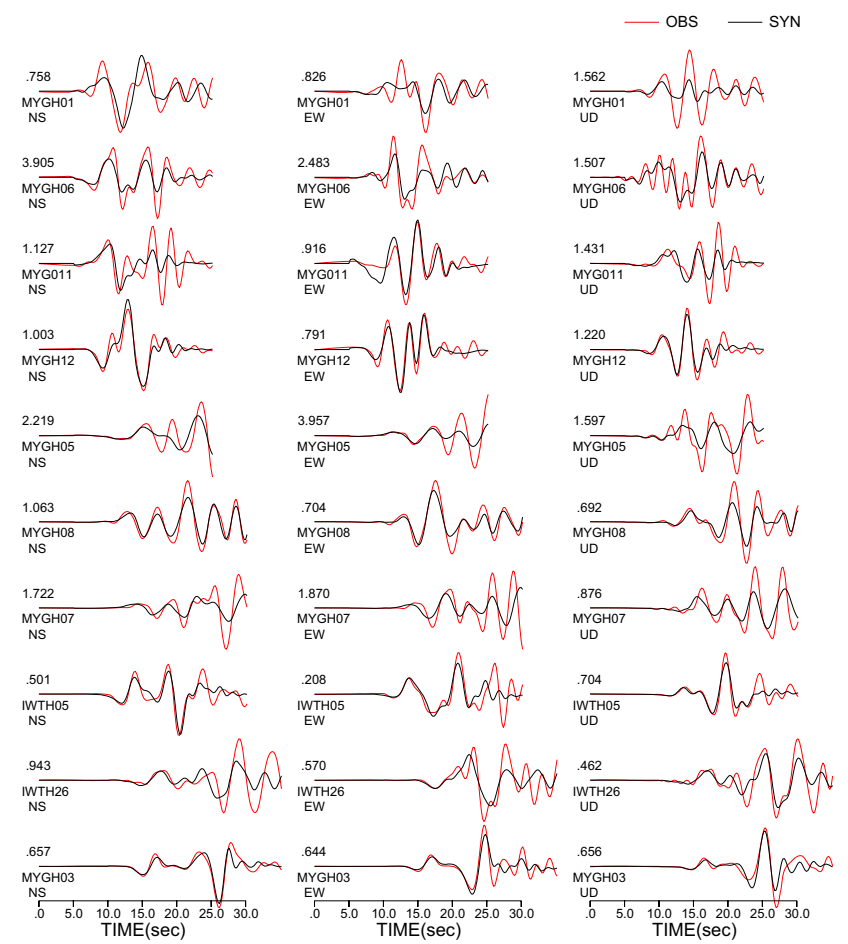

Fig. 5. Comparison of the observed and synthetic seismograms for the mainshock.

The resultant slip distribution in Fig. 3(b) is drawn with contours at intervals of $0.2 \mathrm{~m}$. The rupture propagated from the hypocenter to the north. Although the slips in the southern subplane are small except for a slip of $0.6 \mathrm{~m}$ near the northeastern edge, large slips about $1.0 \mathrm{~m}$ are recovered in a shallow part of the northern subplane. The total seismic moment is $1.9 \times 10^{18} \mathrm{Nm}\left(M_{\mathrm{W}} 6.1\right)$.

We plot the aftershocks with magnitudes of two or larger during the period from the mainshock to the largest aftershock. There are many aftershocks in the eastern 


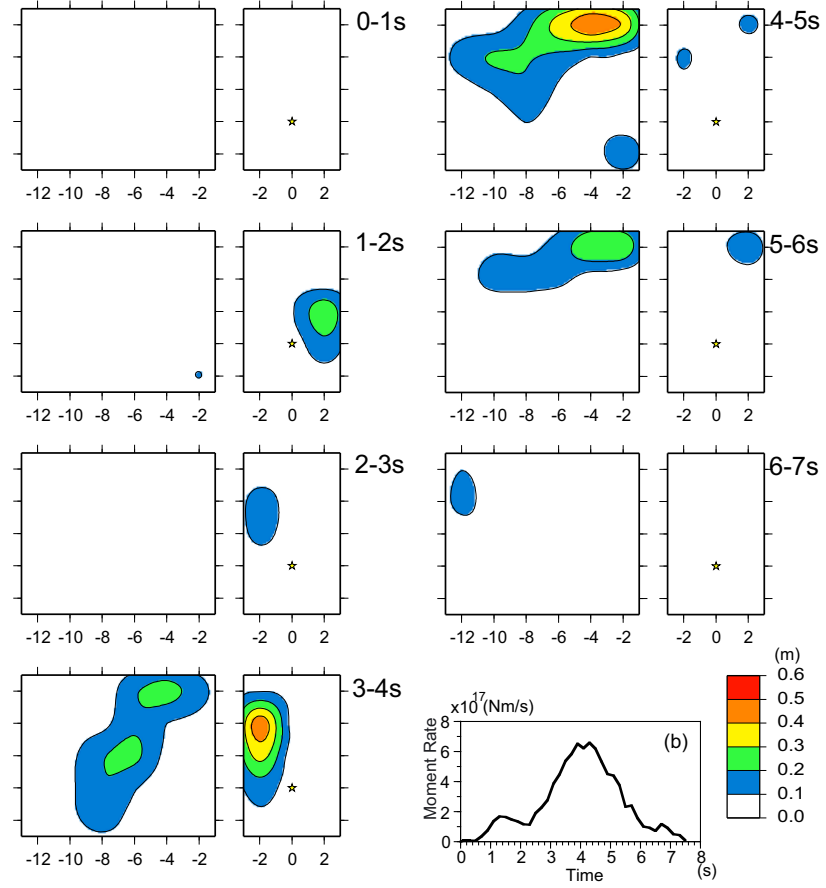

Fig. 6. Snapshots of slip distribution during each of the $1 \mathrm{~s}$ time windows and (b) the total moment rate function.

part of the southern subplane, where the rupture traveled through, though there was no aftershock before the mainshock (Fig. 3(a)). On the north subplane, aftershocks occurred around the large-slip zone (asperity) and in deep, western parts. Mendoza and Harzell (1988) studied the relation between aftershock patterns and distributions of coseismic slip and stated that aftershocks occur mostly outside of or near the edges of main slip regions. Although we have to pay attention to the grid size ambiguity and other slight errors, it seems that the aftershocks are distributed around the asperities on both subplanes, and it is consistent with their result. The agreement between the observed and synthetic seismograms in Fig. 5 is better than in Fig. 4 for the foreshock. We still find slight disagreement at the basin stations.

Figure 6 shows snapshots of the rupture history during the mainshock. The slip began on the southern subplane and propagated to the north and south in the 1-2 and 2$3 \mathrm{~s}$ windows. When the northward propagation reached the shallow portion in the 3-4 s window, the northern subplane started being ruptured in the 4-5 s window. The rupture in the shallow part continued to the 5-6 window with a large slip. These features of the rupture propagation can also be seen in the total moment rate function (Fig. 6(b)).

\subsection{Largest aftershock}

Figure 3(c) shows the slip distribution of the largest aftershock on the northernmost additional subplane. The hypocenter is determined to be $6 \mathrm{~km}$ deep and located in the southern corner of the subplane. The rupture propagated northward to shallower parts with the maximum slip of about $0.15 \mathrm{~m}$. The seismic moment is $1.2 \times 10^{17} \mathrm{Nm}\left(M_{\mathrm{W}} 5.3\right)$, which is smaller than that of the foreshock. The aftershocks after the largest one on July 26 and 27 are distributed only in the south of the hypocenter. This suggests that the largest aftershock occurred in the northern margin of the source re-
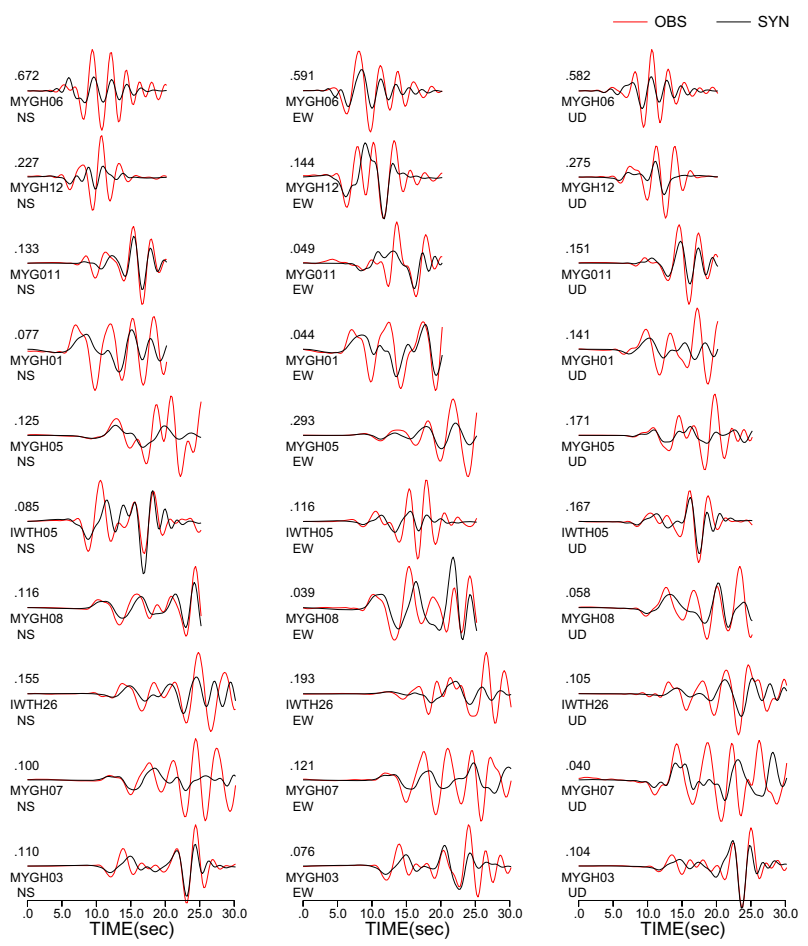

Fig. 7. Comparison of the observed and synthetic seismograms for the largest aftershock.

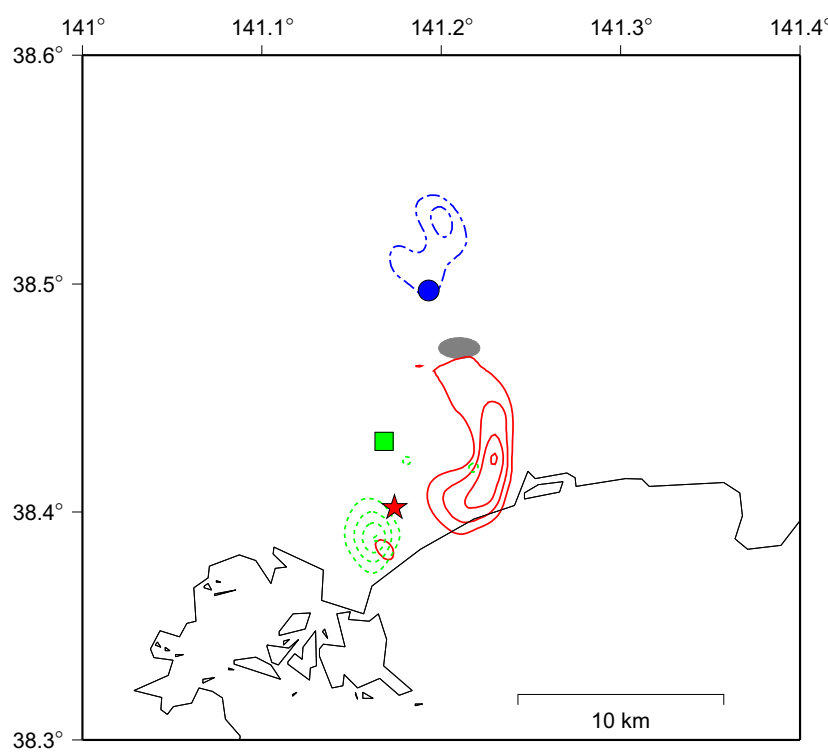

Fig. 8. Superposition of the slip distributions for the foreshock, the mainshock and the largest aftershock. Green broken lines, red solid lines and blue dashed lines show the slip distributions of the foreshock, the mainshock and the largest aftershock, respectively. The symbols of square, star, and circle denote the epicenter of the foreshock, the mainshock, and the largest aftershock, respectively. The contour interval is $0.2 \mathrm{~m}$ for the mainshock, and $0.05 \mathrm{~m}$ for the foreshock and largest aftershock. The shaded ellipse denotes the location of Hirobuchi district.

gion. The agreement of the observed and synthetic seismograms in Fig. 7 is somewhat worse than in Fig. 4 for the foreshock, probably because the structure around the largest aftershock is rather different from that around the foreshock and mainshock, and it is not so appropriate to use the same 1-D models. 


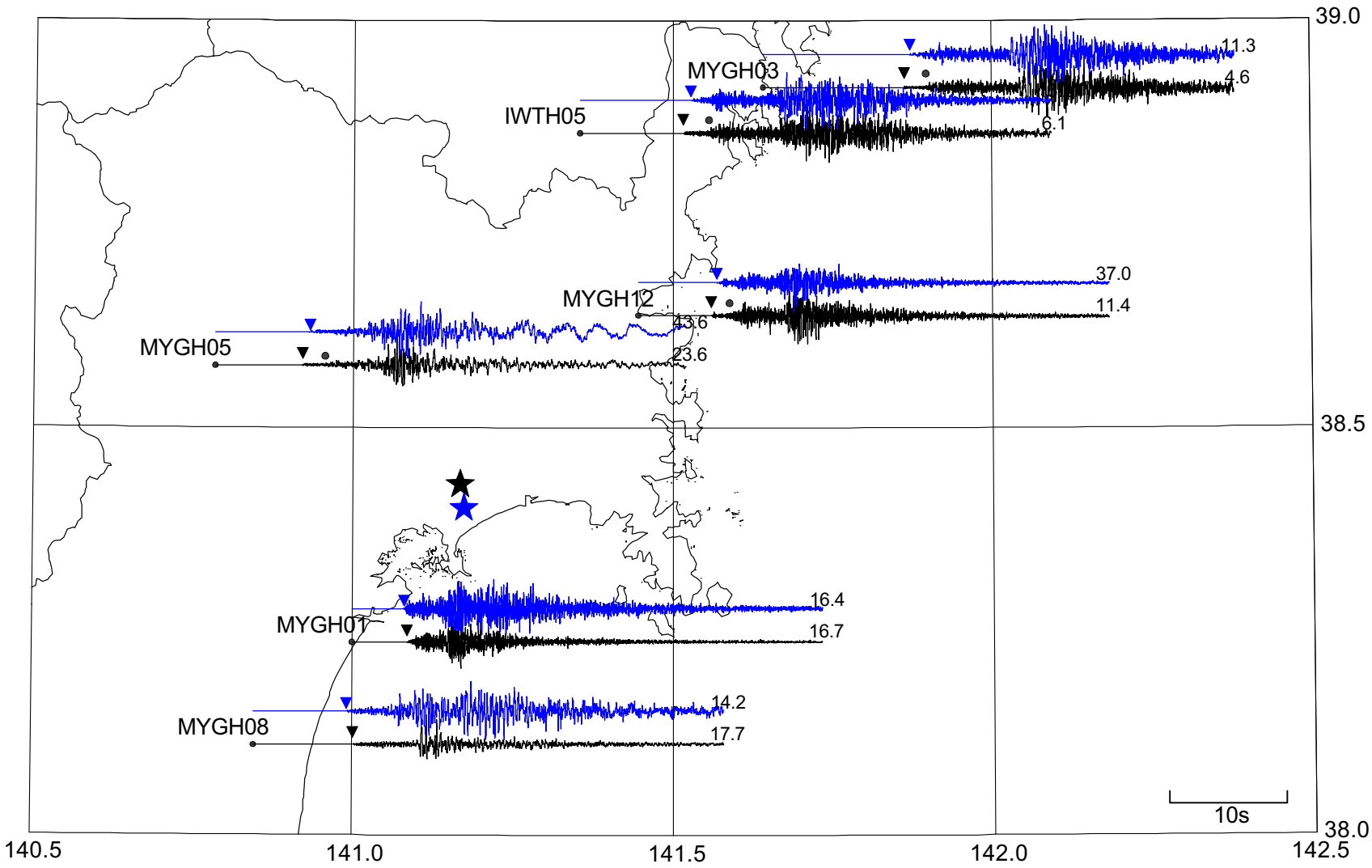

Fig. 9. Radial acceleration seismograms observed at the stations. The upper and lower traces are of the mainshock and of the foreshock, respectively. The traces are normalized to their peak amplitudes and the values are plotted at the end of each trace in $\mathrm{cm} / \mathrm{s}^{2}$. Reverse triangles indicate the arrival time. Filled circles plotted on the traces of the foreshock are the end of initial phase. Blue and black stars are the epicenters of the mainshock and the foreshock, respectively.

\section{Discussion and Conclusions}

To discuss the interaction of the foreshock, the mainshock and largest aftershock, all the results of the waveform inversions are superimposed in Fig. 8. The contour interval is $0.2 \mathrm{~m}$ from $0.4 \mathrm{~m}$ for the mainshock, and is $0.05 \mathrm{~m}$ from $0.1 \mathrm{~m}$ for the foreshock and largest aftershock. The epicenters of the foreshock, mainshock and largest aftershock are denoted by a square, star and circle, respectively. Although the maximum slips of these earthquakes are significantly different, the major slip regions of the three earthquakes are not overlapped each other. From the obtained fault geometry and slip distributions, the earthquake sequence is summarized as follows. The rupture of the foreshock was initiated in a deep portion of the fault, and it propagated toward the south with a strike of NE-SW. The rupture of the mainshock was then initiated near the edge of the asperity of the foreshock, and propagated toward the northern subplane. During the mainshock rupture, the fault strike changed from NE-SW to N-S. The rupture of the largest aftershock was initiated near the zone where the mainshock was terminated. The fault strike of the largest aftershock was NW-SE, and so the earthquake sequence is considered to be a result of seismic activity on a fault curved along strike with bow shape. Okada et al. (2003) also inferred a similar image of the fault rupture from the aftershock activity.

Since the epicenters and fault geometry were determined relying on other investigations, we examine the positional relationship between the epicenters and asperities using the ob- served seismograms. Some radial acceleration seismograms are plotted on the map in Fig. 9, where the upper and lower traces are of the mainshock and foreshock, respectively. All the waveforms begin at the origin time of the mainshock or foreshock. At the stations in the north of the source region, the foreshock motion arrived earlier than the mainshock motion, but at the stations in the south, the mainshock motion arrived earlier. These imply that the foreshock epicenter is located in the north of the mainshock epicenter. Looking at the portions of large amplitudes in the waveforms, we find that their duration is almost the same for the mainshock and foreshock at the northern stations, while the duration for the mainshock is longer than that for the foreshock. These imply that the rupture of the foreshock propagated toward the south and the rupture of the mainshock propagated toward the north. In addition, we can find small arrivals indicated with solid circles in the foreshock waveforms at the northern stations, though they are not found in the southern waveforms clearly. This implies that the asperity of the foreshock is located in the south away from the epicenter. All the aspects mentioned above are consistent with the positional relationship between the epicenters and the asperities in our result.

It is somewhat strange that, although the rupture of the foreshock propagates to the south, the asperity of the mainshock are situated in the north of the foreshock hypocenter. This complicated fault rupture strongly reflects the complex fault geometry. Since the hypocenter of the foreshock is lo- 
cated near the northern end of the southern subplane, the rupture cannot propagate toward the northern subplane, which has different strike and dip from those of the southern subplane. As mentioned above, the mainshock rupture started around the foreshock asperity in the center of the southern subplane. Accordingly, it could propagate to the north subplane, but stopped in front of the source area of the largest aftershock, because the area has different strike and dip from those of the northern subplane. This area was then ruptured during the largest aftershock.

The hypocenter of the mainshock is located near the edge of the asperity of the foreshock. Mori (1996) studied the source processes of the 1992 Joshua Tree Earthquake (M6.1) and its foreshock (M4.3), which occurred two hours before the mainshock, and concluded that the rupture of the mainshock was initiated near the edge of the ruptured region by the foreshock. Okada et al. (2001) studied the source processes of the M5.0 earthquake and its M3.8 foreshock, which occurred near the bottom of the Nagamachi-Rifu fault in 1998. They showed that the rupture area of foreshock does not strongly overlap with the asperities of the mainshock. These results are consistent with the relation of the foreshock and main shock in this study.

Many houses collapsed and more than 600 people were injured during the earthquake sequence. From a field survey carried out immediately after the earthquake sequence, Sakai et al. (2003) reported that the most severe damage was observed in the Hirobuchi district of the Kanan town. This district is situated in the north of the asperity of the mainshock on the northern subplane. Therefore, the directivity effect of the northward rupture propagation could result in this damage. Accelerations over $1 \mathrm{G}$ were also observed at some stations in the source region (JMA, 2003). Since the fault is located in the shallow part of the crust, the slip distribution on the fault and the complex source processes, as seen in Fig. 6, could result in these high accelerations.

If we study more about high-frequency ground motions, details of the source processes are required. However, a waveform inversion with 1-D Green's functions has only limited resolution. We have to introduce empirical Green's functions (e.g., Ide, 1999; Okada et al., 2001) or theoretical 3-D Green's functions (Koketsu et al., 2003). Such a study will be carried out in the future.

Acknowledgments. We thank NIED for the strong motion records from K-NET and KiK-net and the mechanism solutions from F-net and Hi-net. We are also grateful to JMA for the hypocenter list. We appreciate the late Prof. Masayuki Kikuchi and Dr. Yoshiko Yamanaka for their valuable suggestions and discussions. Critical reviews by Dr. Gene Ichinose and anonymous reviewer were very helpful and improved this manuscript.

\section{References}

Akaike, H., Likelihood and Bayes procedure, in Bayesian Statistics, edited by J. M. Bernardo et al., pp. 143-166, Univ. Press, Valencia, Spain, 1980. Aoi, S., K. Obara, S. Hori, K. Kasahara, and Y. Okada, New strong- motion observation network: KiK-net, Eos Trans. AGU, 81(48), Fall Meet. Suppl., Abstract S71A-05, 2000.

Fukuyama, E., M. Ishida, D. S. Dreger, and H. Kawai, Automated seismic moment tensor determination by using on-line broadband seismic waveforms, Zisin, 51, 149-156, 1998 (in Japanese with English abstract).

Hasegawa, A., N. Umino, and A. Takagi, Double-planed structure of the deep seismic zone in the northeastern Japan arc, Tectonophys, 47, 43-58, 1978.

Ide, S., Source process of the 1997 Yamaguchi, Japan, earthquake analyzed in different frequency bands, Geophys. Res. Lett., 26, 1973-1976, 1999.

Iwasaki, T., T. Yoshii, T. Moriya, A. Kobayashi, M. Nishiwaki, T. Tsutsui, T. Iidaka, A. Ikami, and T. Masuda, Precise P and S wave velocity structures in the Kitakami massif, Northern Honshu, Japan, from a seismic refraction experiment, J. Geophys. Res., 99, 22187-22204, 1994.

JMA, On seismic intensity, 238 pp, Gyosei, Tokyo, 1996 (in Japanese).

JMA, Some reports for the 2003 Miyagi-ken Hokubu earthquake sequence, http://www.seisvol.kishou.go.jp/eq/2003_07_26_miyagi/index.html, 2003 (in Japanese).

Kinoshita, S., Kyoshin Net (K-NET), Seismol. Res. Lett., 69, 309-332, 1998.

Kohketsu, K., The extended reflectivity method for synthetic near-field seismograms, J. Phys. Earth, 33, 121-131, 1985.

Koketsu, K., Hypocenter determination with non-negative depth, Zisin, 42, 325-331, 1989 (in Japanese with English abstract).

Koketsu, K., T. Ohno, and Y. Ikegami, Rupture process inversion using 3-D Green's functions: the 1995 Kobe earthquake revisited, EOS Trans. AGU, 84, Fall Meet. Suppl., Abstract S42H-07, 2003.

Mendoza, C. and S. H. Hartzell, Aftershock patterns and main shock faulting, Bull. Seismol. Soc. Am., 78, 1438-1449, 1988.

Mori, J., Rupture directivity and slip distribution of the M 4.3 foreshock to the 1992 Joshua Tree earthquake, southern California, J. Geophys. Res., 86, 805-810, 1996.

NIED, Earthquake mechanism information, http://www.hinet.bosai.go.jp/ topics/miyagi030726/, 2003.

Okada, T., N. Umino, Y. Ito, T. Matsuzawa, A. Hasegawa, and M. Kamiyama, Source processes of 15 September 1998 M 5.0 Sendai, Northern Japan, earthquake and its M 3.8 foreshock by waveform inversion, Bull. Seismol. Soc. Am., 91, 1607-1618, 2001.

Okada, T., N. Umino, and A. Hasegawa, Rupture process of July 2003 northern Miyagi earthquake sequence, NE Japan, estimated from doubledifference hypocenter locations, Earth Planets Space, 55, 741-750, 2003.

Olson, A. H. and R. J. Apsel, Finite faults and inverse theory with application to the 1979 Imperial Valley earthquake, Bull. Seismol. Soc. Am., 72, 1969-2001, 1982.

Sakai, Y., K. Koketsu, T. Kanno, and Y. Nakamura, Building damage by the 2003 Miyagi-oki and Miyagi-ken Hokubu earthquake, and character of strong-motion, Abstract for the annual meeting of Japan association for earthquake engineering, 2003 (in Japanese).

The headquarters for Earthquake Research Promotion, About the strong-motion evaluation for supposing the Miyagi-oki earthquake, http://www.jishin.go.jp/main/kyoshindo/03jun_miyagi/index.htm, 2003 (in Japanese).

Tohoku University, Report papers for the 153rd meeting of the Coordinating Committee for Earthquake Prediction, 2003 (in press).

Waldhauser, F. and W. L. Ellsworth, A double-difference earthquake location algorithm: method and application to the Northern Hayward fault, California, Bull. Seismol. Soc. Am., 90, 1353-1368, 2000.

Yamanaka, Y. and M. Kikuchi, EIC seismological notes, No. 137, http:// wwweic.eri.u-tokyo.ac.jp/EIC/EIC_News/030725.gif, 030725M2.gif and 030726.gif, 2003.

Yoshida, S., K. Koketsu, B. Shibazaki, T. Sagiya, T. Kato, and Y. Yoshida, Joint inversion of near- and far-field waveforms and geodetic data for the rupture process of the 1995 Kobe earthquake, J. Phys. Earth, 44, 437454, 1996.

K. Hikima (e-mail: hikima@eri.u-tokyo.ac.jp) and K. Koketsu 